\title{
Alterations in vasopressin regulation in Alzheimer's disease
}

\author{
GUIDO NORBIATO, MAURIZIO BEVILACQUA, FRANCESCO CARELLA,* \\ ENRICA CHEBAT, UMBERTO RAGGI, PIERLUIGI BERTORA, \\ MARIA PIA GRASSI, * ALFONSO MANGONI*
}

From the Servizio di Endocrinologia and Clinica Neurologica* Ospedale L.Sacco (Vialba) Milano, Italy

SUMMARY A decreased concentration of vasopressin (AVP) in the plasma of patients with Alzheimer's disease has been shown recently and suggests damage to hypothalamic neurosecretory cells. To verify this, osmolar and hypotension (sodium nitroprusside) stimulations on AVP release were applied. The effect of metoclopramide, a powerful stimulator of AVP, was also assessed. Patients with Alzheimer's disease released AVP normally after hypotension. However, AVP response to osmotic stimulation was altered in eight out of 10 patients, owing to low osmoreceptor sensitivity and/or high threshold. Metoclopramide increased AVP in controls but not in patients. Normal AVP response to hypotension in patients with Alzheimer's disease makes it unlikely that there is a significant anatomical loss or damage of hypothalamic neurosecretory cells. Alterations in osmoreceptor function and AVP unresponsiveness to metoclopramide point to damage in the control of AVP release in Alzheimer's disease.

A possible injury in the non-hormonal AVP system in Alzheimer's disease has been suggested by the recent finding of a reduced AVP concentration in CSF and in brain tissue. ${ }^{1-4} \mathrm{~A}$ decrease in plasma hormonal AVP has been also reported, suggesting damage as well to the hypothalamic magnocellular neurons and/or the neurotransmitters controlling the secretion of hormonal AVP. ${ }^{4}$

The main mechanisms controlling hypothalamic AVP secretion ${ }^{56}$ are changes in blood osmolality and decrease in blood pressure and/or blood volume. An increase in blood osmolality is sensed by the osmoreceptor sited in the anterior hypothalamus. Impulses are carried from osmoreceptors to vasopressinergic neurons along cholinergic pathways. A decrease in blood pressure stimulates the highpressure carotid baroreceptor which, in turn, releases AVP through noradrenergic and cholinergic pathways; impulses are carried by the glossopharyngeal nerves to the brain stem, nucleus tractus solitarius, locus coeruleus and paraventricular and supraoptic nuclei. ${ }^{6}$ Changes in blood volume act on the cardiopulmonary baroreceptors which stimulate AVP

Address for reprint requests: Professor G Norbiato, Servizio di Endocrinologia, Ospedale L.Sacco (Vialba), Via GB Grassi 74, 20157 Milano, Italy.

Received 20 November 1987 and in revised form 5 February 1988. Accepted 16 February 1988 release through the cervical vagal pathways and the cholinergic synapses to the hypothalamus. Here, the cholinergic input from the low-pressure volume baroreceptors subserves a tonic excitatory action. ${ }^{78}$

AVP has also been found in other areas of the brain, where it is thought to play a non hormonal role acting as a neurotransmitter. ${ }^{1-4}$ AVP released in the cerebrospinal fluid (CSF-AVP) seems to originate from extra hypothalamic areas. The non-hormonal nature of CSF-AVP is confirmed by the findings of normal CSF-AVP levels in patients with severe neurogenic diabetes insipidus and by the fact that CSF-AVP does not increase after the osmolar or the baroreceptor mediated stimulation. Finally, CSF-AVP displays a circadian rhythm which is absent in plasma AVP. ${ }^{4} 1011$

The purpose of the present study was to evaluate the function of the hypothalamic cells secreting AVP in Alzheimer's disease. Thus, we evaluated AVP response both to changes in plasma osmolality and blood pressure and to metoclopramide. ${ }^{1213}$

\section{Patients and methods}

Our study concerned 10 patients (six male, four female). They were identified and diagnosed as Alzheimer's disease, according to a standard protocol for the diagnosis of Alzheimer's disease validated for Italian population. ${ }^{14}$ Patients' mean age was 70.3, 5.42 (mean, SD; range: 62-77). Disease duration was $2 \cdot 7,1 \cdot 77$ years (range $1-6$ ). All patients 
had non-focal computed brain scans and a Hachinski score $^{15}$ less than 4. Most patients were in an advanced stage of the disease but none was bedridden. Mean Blessed Dementia Scale ${ }^{16}$ was $14 \cdot 7,5 \cdot 49$ (range: $4-23$ ) for the first part of the scale and $7 \cdot 1,8 \cdot 39$ (range: $0-22$ ) for the second part of the scale.

Twelve sex- and age-matched volunteers (eight male, four female; mean age 65 years, range 55-80) acted as controls. Each subject adhered to a controlled 1800-2000 Cal diet containing $130 \mathrm{mmol}$ sodium and $60-80 \mathrm{mmol}$ potassium for a week before and during the study. The diet included at least $2000 \mathrm{ml}$ water. Neither patients nor subjects had renal disease or diabetes mellitus or any other associated illness. They had no evidence of dehydration or malnutrition and were drug-free for at least 15 days preceding the study. Blood pressure was normal in both Alzheimer patients and controls.

Before starting the study, serum and urinary creatinine, $\mathrm{Na}, \mathrm{K}, \mathrm{Cl}$, plasma osmolality, urinary osmolality, urinary volume, plasma renin and aldosterone (both in recumbent position) $)^{17}$ were evaluated in both patients and subjects. Plasma osmolality was measured (by evaluating freezing point depression) with an osmometer (Fiske Co., Burlington, Ma.). By using precautions as previously described ${ }^{18}$ an intrassay variability of $0.5-0.7 \%$ on 10 determinations was obtained. Arginine vasopressin was measured by radioimmunoassay as previously described. ${ }^{12}{ }^{13}$ Plasma renin activity and plasma aldosterone were measured as previously reported. ${ }^{121318}$ Informed consent was obtained from normal subjects and from patients when possible: close relatives of the patients gave informed consent otherwise.

\section{Sodium nitroprusside infusion tes}

The subjects remained recumbent in bed and fasting from $2200 \mathrm{~h}$. From $0830 \mathrm{~h}$ blood pressure was taken every 5 minutes using a sphygmomanometer. Heart rate was recorded by counting radial pulse. At $0900 \mathrm{~h}$ an infusion of sodium nitroprusside was started through intravenous catheter. The infusion rate was determined by a Howard pump and increased every ten minutes from an initial dose of 0.05 $\mu \mathrm{g} / \mathrm{kg} /$ minute to a maximum dose of $1.2 \mu \mathrm{g} / \mathrm{kg} /$ minute. During sodium nitroprusside infusion blood pressure and heart rate were recorded every two minutes. The infusion was discontinued when a decrease in mean arterial pressure (MAP), greater than $30 \mathrm{~mm} \mathrm{Hg}$, was observed or when heart rate increased by more than 25 beats/minute. The number of sodium nitroprusside infusion steps ranged between five and eight for each subject. Two samples of venous blood for AVP determination were drawn from a catheter placed in the controlateral forearm during the last 15 minutes of the perfusion period and one sample of venous blood was drawn during the eighth minute of each infusion period (that is, 2 minutes before the next increase).

\section{Hypertonic saline infusion test}

The subjects remained recumbent in bed and fasting from $2200 \mathrm{~h}$. Two polyethylene indwelling venous catheters were placed in each antecubital vein and then three baseline venous samples were drawn before the saline infusion had started. At $0900 \mathrm{~h}$ the subjects were given a hypertonic saline infusion $(0.05 \mathrm{ml} / \mathrm{kg} / \mathrm{min} 5 \% \mathrm{NaCl})$. Blood pressure was monitored every five minutes during the 30 minutes preceding the test and throughout the infusion period. Blood vasopressin and osmolality determinations were taken every 20 minutes during the infusion, which lasted 180 minutes.

\section{Metoclopramide test}

The subjects remained recumbent in bed and fasting from $2200 \mathrm{~h}$. At $0900 \mathrm{~h}$ an indwelling needle was inserted and kept patent with a slow infusion of $0.9 \% \mathrm{NaCl}$. Metoclopramide ( $20 \mathrm{mg}$ in $2 \mathrm{ml}$ saline) was injected in 2 minutes and venous samples for plasma vasopressin and osmolality were taken at frequent intervals. Blood pressure and heart rate were determined at frequent intervals before and during the test.

\section{Statistical methods}

Metoclopramide data were evaluated by ANOVA. Saline infusion data were submitted to simple regression analysis.

\section{Results}

Values of creatinine, $\mathrm{Na}, \mathrm{K}, \mathrm{Cl}$, plasma and urine osmolality, urinary output, plasma renin and aldosterone found in controls and in patients are reported in table 1 . There were no significant differences between the two groups.

\section{Peripheral haemodynamics and AVP responses to sodium nitroprusside}

Sodium nitroprusside caused dose-dependent reduc-

Table 1 Baseline values of mean blood pressure (mean BP), serum creatinine, $\mathrm{Na}, \mathrm{K}, \mathrm{Cl}$, plasma osmolality (pOsm), urin' osmolality ( $\mathrm{uOsm})$, urinary output, plasma renin activity (PRA) and plasma aldosterone in 10 patients with Al=heimer's dise'ase and 12 sex-and age-matched elderly subjects (mean, SD)

\begin{tabular}{|c|c|c|c|c|}
\hline & Aged controls & Normal range & Alzheimer & $p$ \\
\hline $\begin{array}{l}\text { Mean BP }(\mathrm{mm} \mathrm{Hg}) \\
\text { Creatinine }(\mathrm{mg} / \mathrm{dl}) \\
\text { Na }(\mathrm{mmol} / \mathrm{l}) \\
\mathrm{K}(\mathrm{mmol} / \mathrm{l}) \\
\mathrm{Cl}(\mathrm{mmol} / \mathrm{l}) \\
\mathrm{pOsm}(\mathrm{mmol} / \mathrm{kg}) \\
\text { uOsm }(\mathrm{mmol} / \mathrm{kg}) \\
\text { Ur Output }(\mathrm{ml} / \mathrm{min}) \\
\text { PRA* }\left(\mathrm{ng} / \mathrm{ml}^{\prime} / \mathrm{h}\right) \\
\text { Aldosterone* }(\mathrm{pg} / \mathrm{ml})\end{array}$ & $\begin{array}{c}87,10 \\
0 \cdot 8,0 \cdot 05 \\
138,3 \\
4 \cdot 7,0 \cdot 1 \\
98,0 \cdot 2 \\
289,0 \cdot 1 \\
787,54 \\
2 \cdot 5,0 \cdot 3 \\
1 \cdot 7,0 \cdot 05 \\
105,15\end{array}$ & $\begin{array}{c}0 \cdot 7-1 \cdot 2 \\
136-145 \\
3 \cdot 5-5 \\
97-105 \\
282-295 \\
\\
1 \cdot 5-3 \cdot 5 \\
75-200\end{array}$ & $\begin{array}{c}81,2 \\
0 \cdot 8,0 \cdot 07 \\
139.4 \\
4 \cdot 7,0 \cdot 1 \\
99.0 \cdot 3 \\
292,0 \cdot 2 \\
810.59 \\
2 \cdot 4,0 \cdot 2 \\
1 \cdot 9,0 \cdot 9 \\
107.20\end{array}$ & $\begin{array}{l}0 \cdot 05 \\
\text { NS } \\
\text { NS } \\
\text { NS } \\
\text { NS } \\
\text { NS } \\
\text { NS } \\
\text { NS } \\
\text { NS } \\
\text { NS }\end{array}$ \\
\hline
\end{tabular}

*Recumbent. 


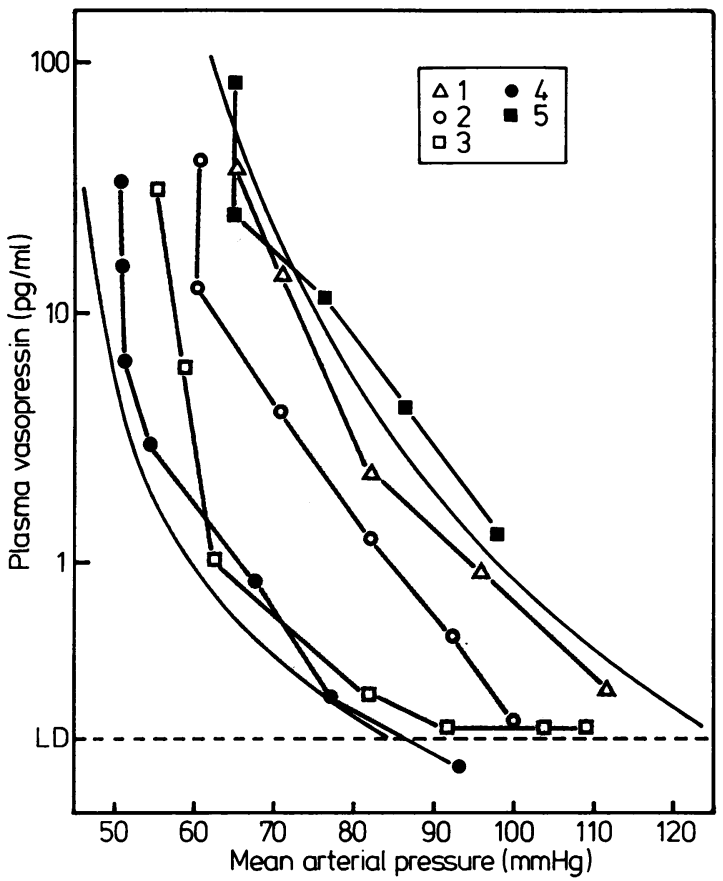

Fig 1 Relation between plasma vasopressin concentration and mean arterial pressure in five patients with Alzheimer's disease submitted to hypotensive stimulus (sodium nitroprusside). Shaded area indicates normal interval values. $L D$ indicates the lower detection limit of the vasopressin assay.

tion in mean arterial pressure both in patients and controls. As shown in fig 1 , where for clarity the results of five out of 10 patients are reported, AVP release was within the range of normality in all patients studied. The heart rate increase was also similar in both groups (data not reported).

\section{AVP response to hypertonic saline infusion}

In control subjects the rise in AVP after saline challenge was significantly related to plasma osmolality

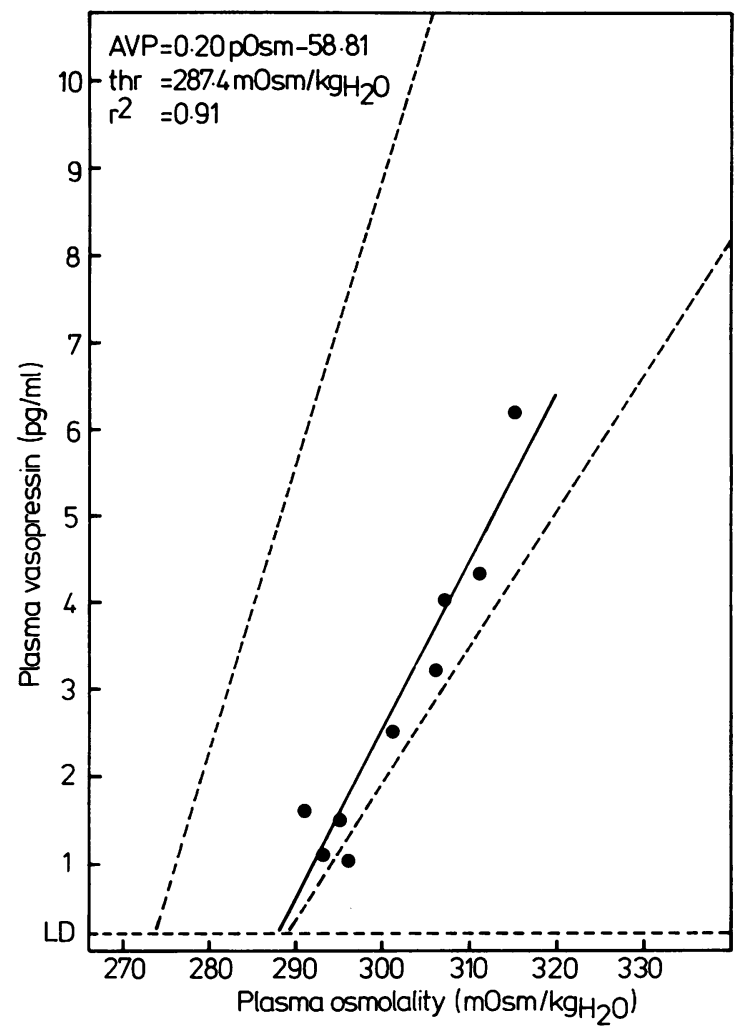

Fig 2 Plasma vasopressin response to osmotic stimulation in a patient with Alzheimer's disease showing normal threshold and sensitivity of vasopressin release control (dashed lines indicate normal interval for vasopressin values versus plasma osmolality).

(pOsm) increase. The regression line between AVP on the ordinate and pOsm on the abscisse was as follows: $\operatorname{AVP}(\mathrm{pg} / \mathrm{ml})=0.23 \mathrm{pOsm}-64.63 ; \mathrm{r}=0.92(\mathrm{p}<$ 0.01 ). The mean "sensitivity" (slope) was $0.23,0.02$ and the mean responsiveness ("threshold") was 281,3 $\mathrm{mmol} / \mathrm{kg}$.

Table 2 Relationship between AVP and plasma osmolality (pOsm) during hypertonic saline infusion in 10 patients with Alzheimer's disease and in 12 age-and sex-matched controls. The osmotic thresholds are also reported

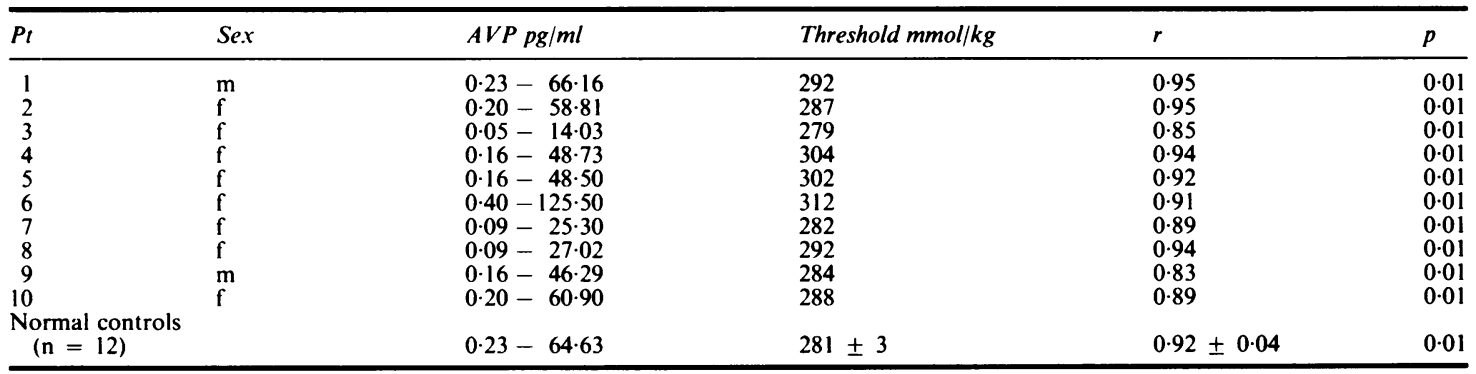




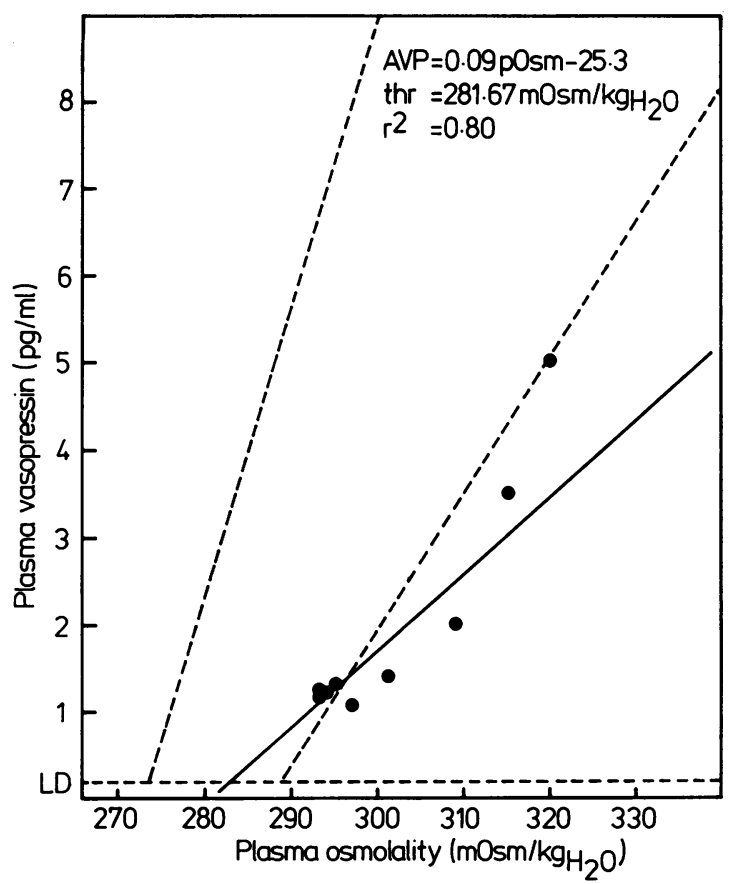

Fig 3 Plasma vasopressin response to osmotic stimulation in a patient with Alzheimer's disease showing normal threshold but reduced sensitivity of vasopressin release control.

In Alzheimer patients the response was quite variable (table 2 and figs 2, 3, 4, 5). Sensitivity was low in six patients (Nos 3, 4, 5, 7, 8, 9); threshold was increased in five patients (Nos $1,4,5,6,8)$. Three patients (Nos $4,5,8)$ displayed both features.

Haemodynamic and AVP responses to metoclopramide After metoclopramide injection, control subjects showed a rise in plasma vasopressin that was significant at 10 minutes $(\mathrm{p}<0.01)$ and peaked at 30 minutes $(\mathrm{p}<0.01)$. Plasma vasopressin then decreased and returned to base levels at 60 minutes. AVP response to metoclopramide was completely absent in patients with Alzheimer's disease $(\mathrm{p}<0.01$ vs controls at times $+10,+20,+30 \mathrm{~min})$. Plasma osmolality, blood pressure and heart rate did not change in any of the subjects studied (fig 6).

\section{Discussion}

Our results showed that Alzheimer patients had an impaired response to osmotic stimuli and were unable to release AVP after metoclopramide. In contrast, they showed normal vasopressin response to nitroprusside-induced hypotension. Also, Alzheimer's disease patients showed a decreased

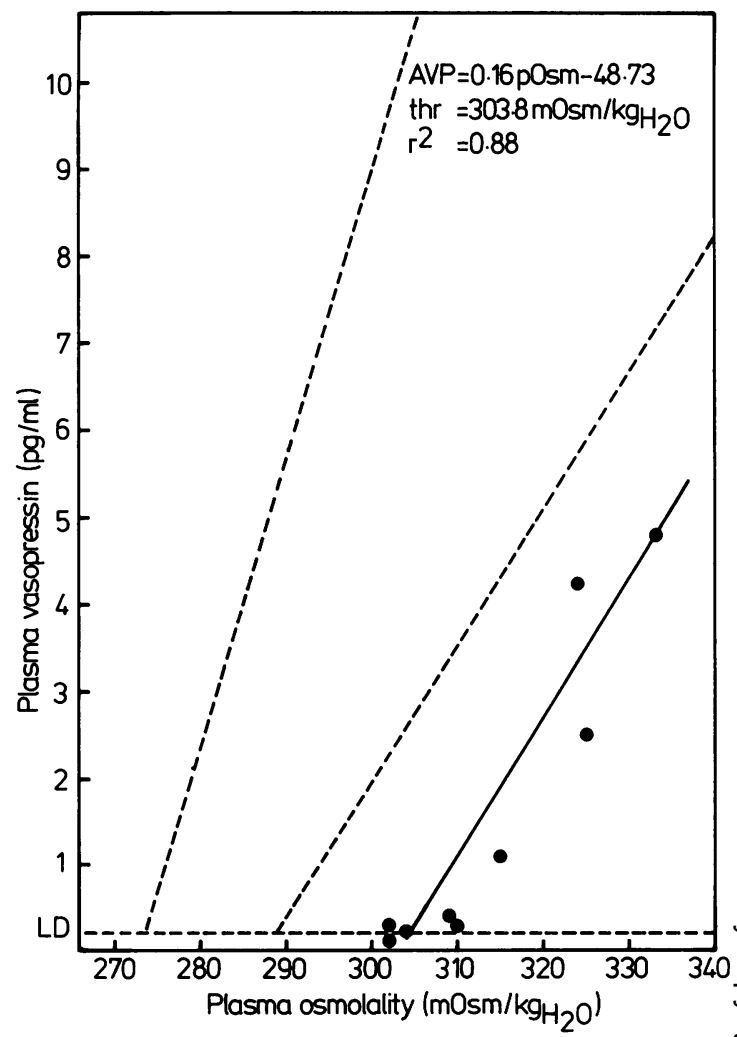

Fig 4 Plasma vasopressin response to osmotic stimulation in a patient with Alzheimer's disease showing normal sensitivity but right-shift in osmotic threshold of vasopressin release control.

osmolar sensitivity and/or enhanced osmolar threshold of AVP. Diminished sensitivity to osmolar stimuli may be observed in diabetes insipidus due to a loss of magnocellular neurons. ${ }^{19}$ However, normal response to hypotension makes it unlikely, in our view, that there was a significant anatomical damage to magnocellular neurons in our patients. This possibility, however, cannot be ruled out by the present study as an increased secretion of surviving cells could produce a normal response. Alternatively, an alteration in the synthesis, storage or action of neurotransmitter at any synapse between the osmoreceptor and the neurohypophysis might account for the reduced sensitivity we observed. Such an alteration might also explain the enhanced AVP threshold observed in the majority of our patients. In fact, an increase in the threshold usually implies a resetting of the osmoreceptor mechanism controlling vasopressin secretion, which suggests a disturbance to the osmoreceptor itself rather than damage to the secretory cells. While clinical conditions associated with an abnormal lowering of the osmoreceptor threshold 


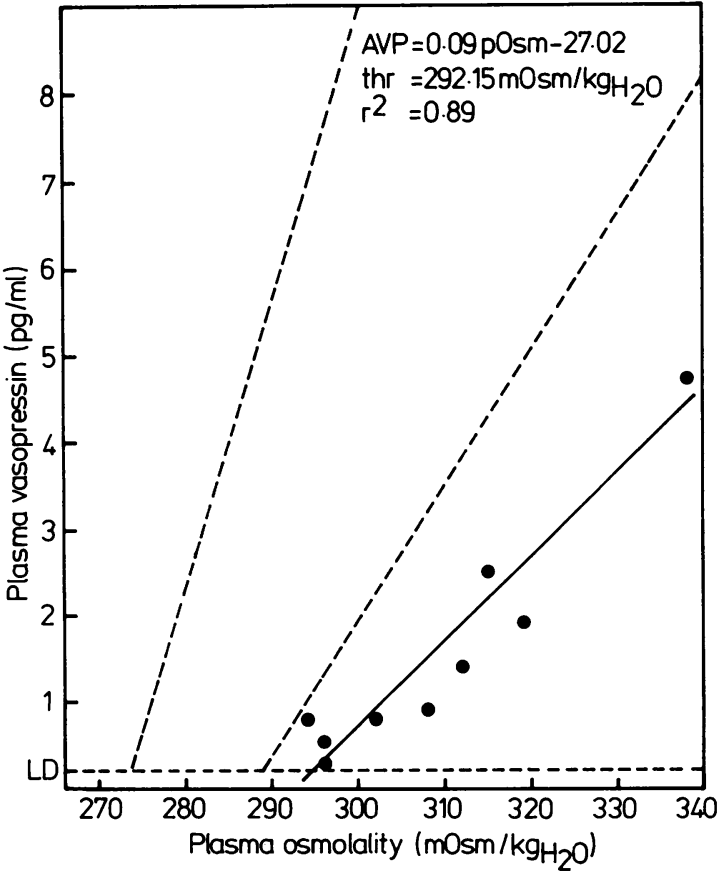

Fig 5 Plasma vasopressin response to osmotic stimulation in a patient with Alzheimer's disease showing both rightshifted threshold and reduced sensitivity of vasopressin release control.

occur with some frequency (hypotension, volume depletion), ${ }^{20}$ an enhanced osmotic threshold is observed only in primary aldosteronism. ${ }^{21}$ However, values of renin and aldosterone were normal according to age in our patients. Resetting of the osmoreceptor mechanism might also be caused by changes in the afferent traffic of neurons regulating AVP release in paraventricular and supraoptic nuclei. ${ }^{7}$ These nuclei receive cholinergic neurons from both osmoreceptors and low-pressure volume baroreceptors, the latter having a tonic excitatory action. It is well recognised that cholinergic neurons are greatly damaged in Alzheimer brains. ${ }^{22} 23$ The clinical relevance of such abnormalities is unknown at present but since AVP threshold coincides with thirstthreshold during osmolar stimulation, ${ }^{24}$ Alzheimer patients with higher osmotic threshold might be more prone to dehydration.

As far as the response to metoclopramide is concerned, we recently demonstrated that its effect on AVP release was not due to its dopaminergic properties since other antidopaminergic agents were unable to release AVP. ${ }^{1213}$ In contrast, cholinomimetic properties of metoclopramide ${ }^{25-28}$ may be important in AVP release. Experimentally, pre-treatment with atropine abolishes AVP release after metoclopramide

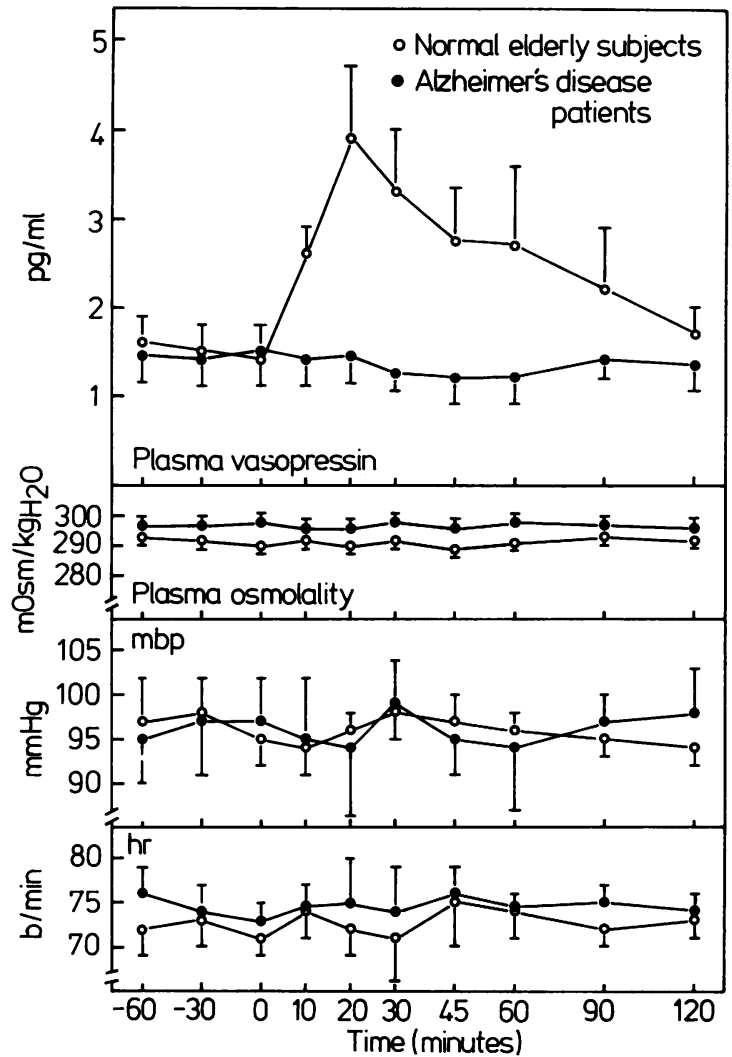

Fig 6 Effect of metoclopramide (20 mg IV) on plasma vasopressin, plasma osmolality, mean blood pressure ( $m b p$ ) and heart rate (hr) in 10 patients with Alzheimer's disease and 12 healthy age-and sex-matched elderly subjects (mean values, $S D$ ).

in rats ( $M$ Iovino and $\mathrm{G}$ Norbiato; unpublished data) suggesting that the releasing action of metoclopramide is mediated through muscarinic receptors. Thus, absence of release of vasopressin after metoclopramide in Alzheimer patients might be an expression of cholinergic impairment as well.

In conclusion, Alzheimer patients had an abnormal AVP response to osmotic stimulation and to metoclopramide. Metoclopramide infusion may offer a safe test to evaluate alterations in AVP control and possibly to monitor cholinergic dysfunction in Alzheimer's disease patients. In that respect, further studies of its sensitivity and specificity are needed, including patients with less severe Alzheimer's disease and with histopathologically proven disease, as well as patients with other pre-senile and senile dementias.

The authors gratefully acknowledge the help of Mrs E Lora for her excellent technical assistance. 


\section{References}

1 Mazurek MF, Growdon JH, Beal FM, Martin JB. CSF vasopressin concentration is reduced in Alzheimer's disease. Neurology 1986;36:1133-7.

2 Rossor MN, Iversen LL, Mountjoy CQ, et al. Arginine vasopressin and choline acetyltransferase in brains of patients with Alzheimer's type senile dementia. Lancet 1980;ii:1367-8.

3 Mann DMA, Yates PO, Marcyniuk B. Changes in Alzheimer's disease in the magnocellular neurones of supraoptic and paraventricular nuclei of the hypothalamus and their relationship to the noradrenergic deficit. Clin Neuropathol 1985;4:127-34.

4 Sorensen PS. Studies of vasopressin in the human cerebrospinal fluid. Acta Neurol Scand 1986;74:81-102.

5 Robertson GL, Athar S, Shelton RL. Osmotic control of vasopressin function. In: Andreoli TE, Grantham JJ, Rector FC Jr, eds. Disturbances in Body Fluid Osmolality. Bethesda: American Physiological Society, 1977:125-48.

6 Schrier RW, Berl T, Anderson RJ, McDonald KM. Nonosmolar control of renal water excretion. In: Andreoli TE, Grantham $\mathrm{JJ}$, Rector FC Jr, eds. Disturbances in Body Fluid Osmolality. Bethesda: American Physiological Society, 1977:149-78.

7 Sawchenko PE, Swanson LW. The organization of noradrenergic pathways from the brainstem to the paraventricular and supraoptic nuclei in the rat. Brain Res Rev 1982;4:275-325.

8 Brent E, Grekin R, Ibsen H, Osterziel K, Julius S. Role of cardiopulmonary mechanoreceptors in ADH release in normal human. Hypertension 1982;6:832-6.

9 Bishop VS, Thamer MD, Schmid PG. Effects of bilateral vagal cold block on vasopressin in conscious dogs. Am J Physiol 1984;246:R566-R569.

10 Reppert SM, Artman HG, Swaminathan S, Fisher DA. Vasopressin exhibits a rhytmic daily pattern in cerebrospinal fluid but not in blood. Science 1981;213:1257-9.

11 Luerssen TG, Robertson GL. Cerebrospinal fluid vasopressin and vasotocin in health and disease. In: Wood JW, ed. Neuro biology of Cerebrospinal Fluid. New York: Plenum, 1980: 613-23.

12 Norbiato G, Bevilacqua M, Chebat E, et al. Metoclopramide increases vasopressin secretion. J Clin Endocrinol Metab 1986;63:747-50.

13 Bevilacqua M, Norbiato G, Chebat E, et al. Osmotic and non- osmotic control of vasopressin release in the elderly: effect of metoclopramide. J Clin Endocrinol Metab 1987;65:1243-7.

14 Amaducci LA, Fratiglioni L, Rocca WA, et al. Risk factors for clinically diagnosed Alzheimer's disease: a case-control study of an Italian population. Neurology 1986;36:922-31.

15 Hachinski VC, Iliff LD, Zilhka E, et al. Cerebral blood flow in dementia. Arch Neurol 1975;32:632-7.

16 Blessed G, Tomlinson BE, Roth M. The association between quantitative measure of dementia and of senile change in the cerebral grey matter of elderly subjects. $\mathrm{Br} J$ Psychiatry 1968;114:797-811.

17 Norbiato G, Bevilacqua M, Raggi U, Micossi P, Moroni C. Metoclopramide increases plasma aldosterone concentration in man. J Clin Endocrinol Metab 1977;45:1313-6.

18 Bevilacqua M, Meroni R, Dagani R, Renesto E, Baruto C, Norbiato G. Role of blood osmolality in the regulation of vasopressin secretion in man: application of a new radioimmunoassay method for vasopressin. $J$ Endocrinol Invest 1985;8:97-101.

19 Robertson GL, Aycinena P, Zerbe RL. Neurogenic disorders of osmoregulation. Am J Med 1982;72:339-53.

20 Cowley AW, Switzer S, Guinn M. Evidence and quantification of vasopressin arterial pressure control system in dogs. Circulation Res 1980;46:58-67.

21 Ganguly A, Robertson G. Elevated threshold for vasopressin release in primary aldosteronism. Clin Res 1980;48:330A.

22 Davies P, Maloney AJ. Selective loss of central cholinergic neurons in Alzheimer's disease. Lancet 1976;ii:1403.

23 Francis PT, Palmer PHD, Sims NR. Neurochemical studies of early-onset Alzheimer's disease. N Engl J Med 1985;313:7-11.

24 Robertson GL. Abnormalities of thirst regulation. Kidney Int 1984;25:460-9.

25 Stadas J, Aune S. The effect of metoclopramide (Primperan) on gastric motility before and after vagotomy in man. Scand J Gastroenterol 1971;6:17-21.

26 Eisner M. Gastrointestinal effects of metoclopramide in man: in vitro experiments with human smooth muscle preparations Br Med J 1968;4:679-80.

27 Hay AM, Man WK. Effect of metoclopramide on guinea pig stomach: critical dependence on intrinsic stores of acetylcholine. Gastroenterology 1979;76:492-6.

28 Schulze-Delrieu K. Metoclopramide. N Engl J Med 1981; 305:28-33. 